13 Driks MR, Craven DE, Celli DR, et al. Nosocomial pneumonia in intubated patients given.sucralfate as compared with antacids or histamine type 2 blockers. $N$ Engl f Med

14 Flaherty J, Kabins SA, Weinstein RA. New approaches to the prevention of infection in intensive care unit patients. In van Saene HKF, Stoutenbeek CP, Lewin P, McA Ledingham I, eds: Infection control by selective decontamination. Berlin Springer Verlag, 1989:184-8.

15 Stoutenbeek CP, van Saene HKF, Miranda DR, Zandstra DF, Langrehr $D$. The effect of oropharyngeal decontamination using topical non absorbable antibiotics on the incidence of nosocomial respiratory tract infections in multiple trauma patients. F Trauma 1987;27:357-64.

SIR, - The discussion on the effect of selective decontamination on mortality in intensive care units ${ }^{1}$ cannot be resolved by an uncritical look at data from currently published studies. Selective decontamination is not a miraculous cure for the critically ill, merely an effective prevention regimen for use in units in which serious nosocomial infection is frequently seen. Research evidence suggests that reductions in mortality as a result of using gastrointestinal decontamination and systemic cefotaxime (SPEAR) are likely to be modest. Regression analysis of data from the Glasgow study ${ }^{2}$ suggested that admission factors as measured by Apache $\mathrm{II}^{3}$ and sepsis ${ }^{+}$scores were of greater importance in deciding outcome than infection acquired in the intensive therapy unit. Only a very large study would show whether a small but important improvement in mortality can be achieved by using selective decontamination. For example, the second international study of

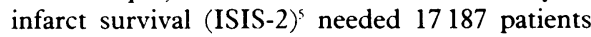
with myocardial infarction to show a $25 \%$ reduction in mortality from streptokinase infusion from $12 \%$ to $9 \cdot 2 \%$.

The ability of a trial to decide between selective decontamination and conventional management in terms of affecting overall mortality relies on the number of deaths rather than the number of patients entered. ${ }^{6}$ Any reduction in mortality as a result of selective decontamination will depend on the incidence of infection acquired in the unit and subsequent mortality. In the Glasgow trial only 10 of 161 controls died in intensive therapy units after acquiring infection in the unit. This represents only a quarter of the 39 deaths in the group. If we consider a hypothetical study comparing selective decontamination with conventional treatment in which the incidence of acquired infection in the controls remains at $24 \%$ in those staying over 48 hours, and the subsequent mortality is $50 \%$, as was seen in our trial, the study would need 3200 admissions to observe 100 deaths in a contro group of 1600 patients after an episode of acquired infection. We would also expect 300 deaths from other causes, giving a total of 400 deaths and 1200 survivors in the control group and a mortality of $25 \%$. If half of the deaths after acquired infection were prevented by selective decontamination (a highly optimistic outcome), resulting in a total of 350 deaths and 1250 survivors in the treatment group, overall mortality would fall by only $3 \%$ to $22 \%$. This would only just achieve a significant result by $\chi^{2}$ testing $(p=0.05,95 \%$ confidence interval 6.06 to $0 \cdot 19$ ). Smaller reductions in mortality would need an even larger study to achieve significance. ${ }^{7}$ To conduct such a study would require the participation of several units, uniform admission and management procedures, and some agreement on the difficult issue of diagnosis of infection, particularly pneumonia

Mortality, however, is not the only criterion that should be looked at. Miranda et al have shown considerable financial savings as a result of selective decontamination of the digestive tract. ${ }^{8}$ We have also seen savings in the use of disposables such as paper gowns, intravenous administration sets, and parenteral nutrition that outweigh the relatively small increase in antibiotic costs. If there continues to be no appreciable problem with antibiotic resistance the present policy of using selective decontamination in all ventilated patients who stay more than 24-48 hours in the intensive therapy unit could be justified based on the economic benefits alone.

JC MCDONALD

Department of Anaesthesia,

Western Infirmary,

1 Sanderson PJ. Selective decontamination of the digestive tract: value in intensive care units not proved. $\mathrm{Br}$ Med $\mathcal{F}$ 1989;299. 1413-4. (9 December.)

2 Ledingham IMA, Alcock SR, Eastaway AT, McDonald JC, Ramsay G, Mackay I. The use of a triple regimen of selective decontamination of the digestive tract, systemic cefotaxim and microbial surveillance for prevention of acquired infection in intensive care. Lancet 1988;i:785-90.

3 Knaus WA, Draper EA, Wagner DP, et al. Apache II: a severity of disease classification system. Crit Care Med 1985;13:818-29. Elbute EA, Stoner HB. The grading of sepsis. $\mathrm{Br} \mathcal{J}$ Surg 1983;70:29-31

5 Second International Study of Infarct Survival Collaborative Group. Randomised trial of intravenous streptokinase, oral aspirin, both or neither among 17187 cases of suspected acute myocardial infarction: ISIS-2. Lancet 1988;ii:349-59.

6 Peto $\mathrm{R}$, Pike MC, Armitage $\mathrm{P}$, et al. Design and analysis of randomised clinical trials requiring prolonged observation of
each patient. 1. Introduction and design. Brf Cancer 1975;34: 585-612.

7 Boag JW, Haybittle JL, Fowler JF, Emery EW. The number of patients required in a clinical trial. $B r \mathcal{F}$ Radiol 1971;44:122-5. 8 Miranda DR, van Sane HKF, Stoutenbeek CP, Zanstra DF. Environment and costs in surgical intensive care units. The implication of selective decontamination of the digestive tract. Acta Anaesthesiol Belg 1983;34:223-31.

\section{Information please}

SIR,-Dr D Clements ${ }^{1}$ presumably missed the letter in which Dr A J Robertson and I commented on the advantages of patients having a unique identification number for all general practice and hospital purposes. ${ }^{2}$

Experience in Tayside has confirmed the potential of such a system for medical audit and resource management. For example, linkage of events such as admissions of patients to different hospitals with different diagnoses (even though the underlying disease process may be the same) is easy if the same patient number is used for case records in each hospital. ${ }^{3}$ Information on survival can also be incorporated as the community health index is updated by mortality data from the registrar general. A further advantage is that confidentiality is enhanced as the basis of linkage is the index number, and no names need be sent to the computer department or need appear on subsequent printouts.

The first step for those south of the Tweed is to abolish the unfortunate separation of district health authorities and family practitioner committees and adopt the Scottish system of having primary care divisions as integral parts of health boards.

Tayside Health Board,

N R WAUGH

I Clements D. Information please. Br Med J. 1990;300:123-4. (13 January.

2 Waugh NR, Robertson AJ. Evaluation of a call programme for cervical cytology screening. Br Med f 1989;299:855. (30 September.)

3 Waugh NR. Amputation in diabetic patients - a review of rates, relative risks and resource use. Community Med 1988;10: $279-88$.

\section{Fibromuscular dysplasia of renal arteries and acute loin pain}

SIR, - The article by Dr Simon J Stinchcombe and colleagues reminds us of the importance of diagnosing arterial occlusion as a rare cause of acute loin pain.' They have, however, overestimated its incidence by placing it at the top of the list of causes of acute loin pain with nonfunctioning kidney. Ureteric obstruction-the commonest cause - is placed last.

We also have misgivings about their proposed method of investigating acute loin pain. Surely a full clinical assessment, urine analysis, and microscopy and plain film radiography should be the initial gambit rather than intravenous urography. Only those patients without evidence of acute pyelonephritis or radio-opaque ureteric calculus require emergency intravenous urography. Of the remainder, those with pyuria, bacteriuria, and fever require ultrasonography to exclude pyonephrosis which would need drainage, and those with a radio-opaque calculus on plain film radiography should be investigated electively, which may include intravenous urography.

The authors do not suggest further investigation of patients with a hydronephrotic, non-functioning kidney. An antegrade pyelogram would not only confirm the presence of obstruction but would also show the level and nature of the obstructing lesion. Finding a normal pelvicaliceal system on ultrasonography does not exclude an obstructive cause. The only further investigation in such patients suggested in the authors' flow chart is angiography. The flow chart also seems to advocate angiography after either renography or computed tomography regardless of the result of either. These investigations therefore do not seem to be contributory. Although renal vein thrombosis may be diagnosed on renal arterial angiography, renal venography is a more appropriate test. Ultrasound examination of the renal veins before any angiography would therefore seem advisable.

Finally, the authors state that if a patient with acute loin pain is found to have a very small kidney no further investigation is warranted. We suggest that a very small kidney is an unlikely source of the patient's symptoms and that another cause should be sought.

M J DUDDY $S$ A BRADLEY S CHAPMAN

Department of Radiology,

Children's Hospital,

Birmingham B16 8ET

1 Stinchcombe SJ, Manhire AR, Bishop MC, Gregson RHS Fibromuscular dysplasia of renal arteries: a neglected cause of acute loin pain. BrMed $\mathcal{F}$ 1990;300: 183-5. (20 January.)

\section{Effective use of regional intensive therapy units}

SIR,-The paper by Dr Jane A M Purdie and colleagues $^{1}$ fails to answer the aims of the trial. Indeed the study design was such that it could not answer the objective of determining the effectiveness of regional intensive therapy units as results from regional units were not compared with those from units in district hospitals.

I am assuming that the legend to the scatter diagram of APACHE score versus duration of admission before transfer is incorrect and that the symbols for survivors and deaths have been inadvertently switched. When all data on this diagram are analysed together by the MannWhitney $U$ test then there is no significant difference between the survivors and those patients who died with regard to duration of illness before transfer. There is also no significant difference in APACHE score between the survivors and those who died. Moreover, of the patients who were transferred 10 days or more after the onset of their illness, 10 survived and nine died. These points refute the authors' suggestion that patients with an APACHE score greater than 10 who have been ill for more than $\mathbf{1 0}$ days should not be transferred to regional intensive therapy units.

I support the concepts outlined in the document 